\title{
Clinical and histopathological profile of basal cell carcinomas of the head and neck: An analysis of 95 cases
}

\author{
Yasemin Yuyucu Karabulut* \\ Department of Pathology, Ankara University, Medical School, Turkey
}

\begin{abstract}
Background/Objective: Basal cell carcinoma (BCC) is the most common form of cancer in Caucasians. The most common type of BCC is the nodular form. This study was undertaken to analyze the all histopathological subtypes and tumor diameter with epidermal ulceration of head and neck localized BCC with regard to sex, age and anatomical distribution in a population from the Mid-Anatolian Region of Turkey.

Methods: Ninety-five patients histopathologically diagnosed with BCC of head and neck at our dermatology and pathology clinics were retrospectively examined and assessed. The diagnosis and subtypes with the tumor diameter and epidermal ulceration were confirmed by two pathologists. Gender, age at excision and location were recorded.

Results: The mean age at excision of a BCC was $69.98 \pm 13.07$ years. The nodular BCC was the most frequent type (23.2\%), followed by the superficial and micronodular types (22.1\%). The micronodular, nodular and superficial BCC occurred more often in males and solid and infiltrative types more often in females. Almost all types showed slight predominance for nose localization. The superficial form was the dominant type on the cheek. The mean tumor diameter is $8.94 \mathrm{~mm}$ with the range of $0.5-38 \mathrm{~mm}$. There was a statistically significant difference between the micronodular with the smaller diameter of $5.25 \mathrm{~mm}$ and the other types of BCC diameter. Epidermal ulceration was observed in most of the patients (77.9\%) and there was not any significant difference among the types of BCC.
\end{abstract}

Conclusion: Our results confirmed the outcomes of the previous reports in the literature. We found that the superficial type of BCC of the head and neck region most commonly occurred on the cheek.

\section{Introduction}

Basal cell carcinoma (BCC) is the most common cancer worldwide in white-skinned populations. Incidence rates vary hugely with geographical location [1]. Despite the high prevalence of this tumor, there is a lack of reliable epidemiological data in most European countries. Recent studies suggest that BCC is not a single entity. It has been hypothesized that BCC occurring at certain body sites or BCC of a particular histological subtype may define certain clinical behavior and it may even have a different etiology [1-5]. Further data from these studies have shown that the histological subtype most commonly occurring on the trunk is the superficial type and that there is a trend towards an increasing proportion of all BCCs to occur on the trunk. These observations have again raised the issue of whether intermittent or cumulative sun exposure or a combination of both initiate and/ or promote BCC occurring on less exposed body sites such as the trunk [2-5]. In 1995, Kricker et al. had postulated an increased risk of BCC from intense 'bursts' of sun exposure that exceeded the risk of a similar exposure spread evenly over the same total period of time [6]. Unfortunately, their large case-control study did not differentiate the histological subtypes of BCC. The histopathological differentiation of BCC subtypes is based on the different growth patterns, which are also the basis of the current classification system suggested by the World Health Organization (WHO). This classification, which has shown practical relevance, broadly distinguishes between nodular, superficial and infiltrative BCC. In addition, micronodular BCC has been separately recognized as a high-risk subtype because of the elevated likelihood of recurrence. Other recognized subtypes of BCC as well as mixed types occur less frequently $[7,8]$. Although BCCs rarely metastasize, costs related to the treatment of BCC are substantial in countries with a high incidence rate such as Australia, and morbidity from certain histological subtypes of BCC can be substantial due to their clinical behavior $[9,10]$. Recurrence rates overall are higher in BCC than in squamous cell carcinoma (SCC) [11]. Infiltrative and micronodular BCCs are considered high-risk histopathological subtypes because they are more likely to be incompletely excised and/or to recur especially on the face where surgical margins might be conservative $[7,9,12]$.

Superficial BCCs have also been classified as 'high risk', because of their propensity to recur as they may be incompletely excised without necessarily showing tumor in the excision margin on histological examination $[11,12]$. Ideally, the reporting of the histopathological subtype of the BCC together with host demographics and body-site information should relate to and enhance clinical information and ultimately improve treatment regimens [9]. In addition, studies on the relationships between these factors could help to clarify the link between sun exposure and BCC $[1,2,13]$. We have analyzed the main characteristics of the most frequent subtypes of BCC together with detailed head and neck site data recorded during two years.

Correspondence to: Yasemin Yuyucu Karabulut, Department of Pathology, Ankara University, Medical School, Turkey, E-mail: yykarabulut@yahoo.com.tr

Key words: head and neck, basal cell carcinoma, histopathological subtype

Received: October 03, 2015; Accepted: October 24, 2015; Published: October 26,2015 


\section{Materials and methods}

Ninety-five facial basal cell carcinoma patients were admitted to the dermatology clinic of our hospital that is a secondary health centre between January 2011 and November 2012. The patients were evaluated retrospectively and demographic data, history of disease, clinical findings were collected from medical records. The pathology slides were classified into one of six following histopathological subtypes: nodular, micronodular, superficial, infiltrative, solid, and adenobasal BCC (Figure 1a-1g). We used the histological parameters as described in WHO for the identification the histopathological subtype of BCCs.

In cases of mixed architecture combining features of superficial lobules plus large areas of nodular BCC, the slides were classified as nodular BCCs. Cases with only a small zone of dermal nodular carcinoma in a large superficial carcinoma were classified in the superficial group. We also checked all data to rule out the possibility of including both a biopsy and a following surgical excision of the same tumor. We used the term nodular BCC when tumor cell clusters showing typical peripheral palisading were present in the dermis. The term superficial BCC was used to define a tumor including buds and

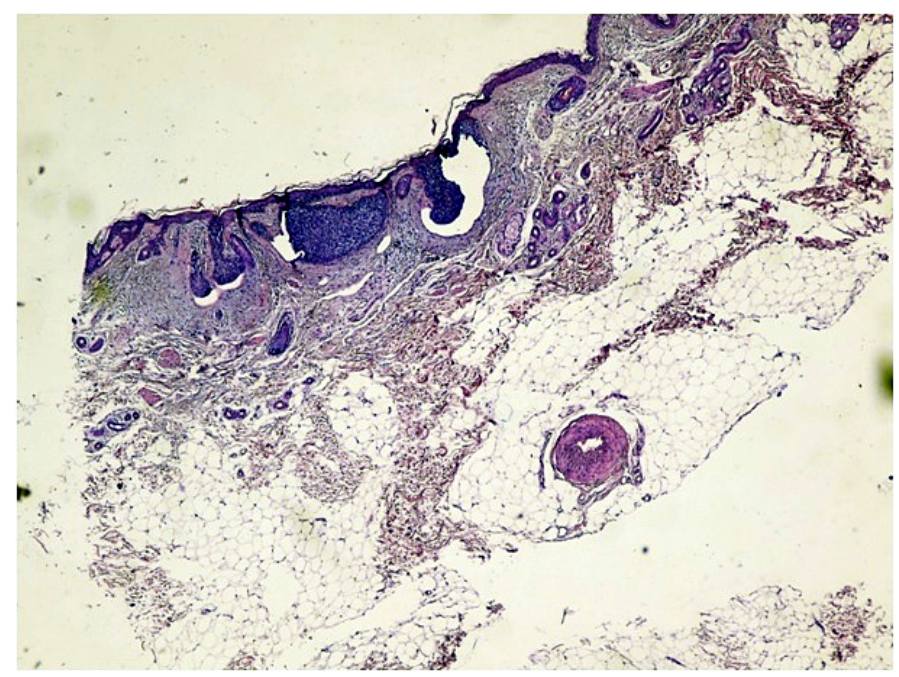

Figure 1a. Micronodular type of BCC (H\&E x 100).

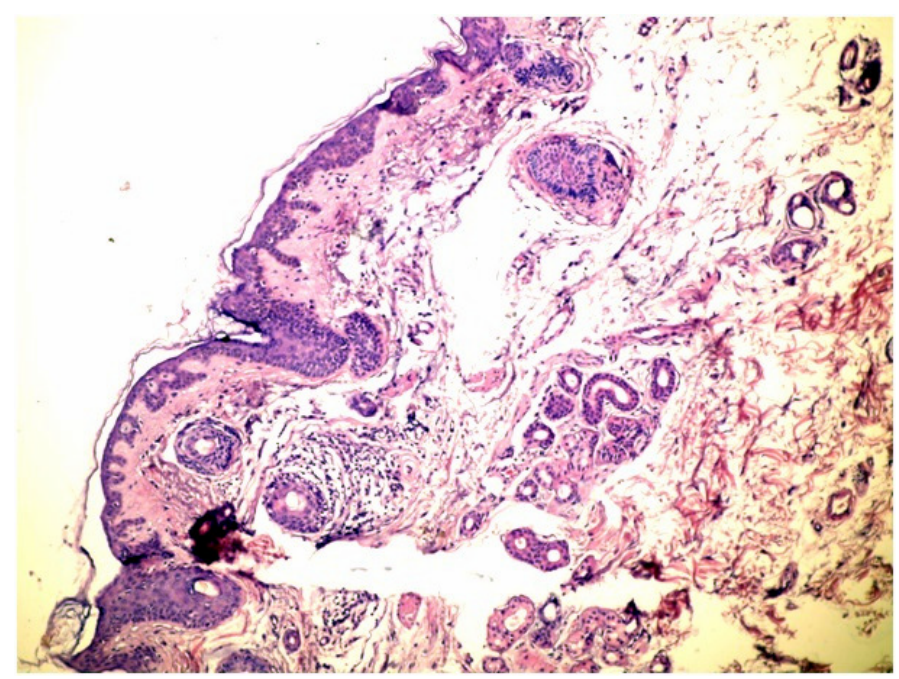

Figure 1b. Superficial spreading type of BCC (H\&E x 100).

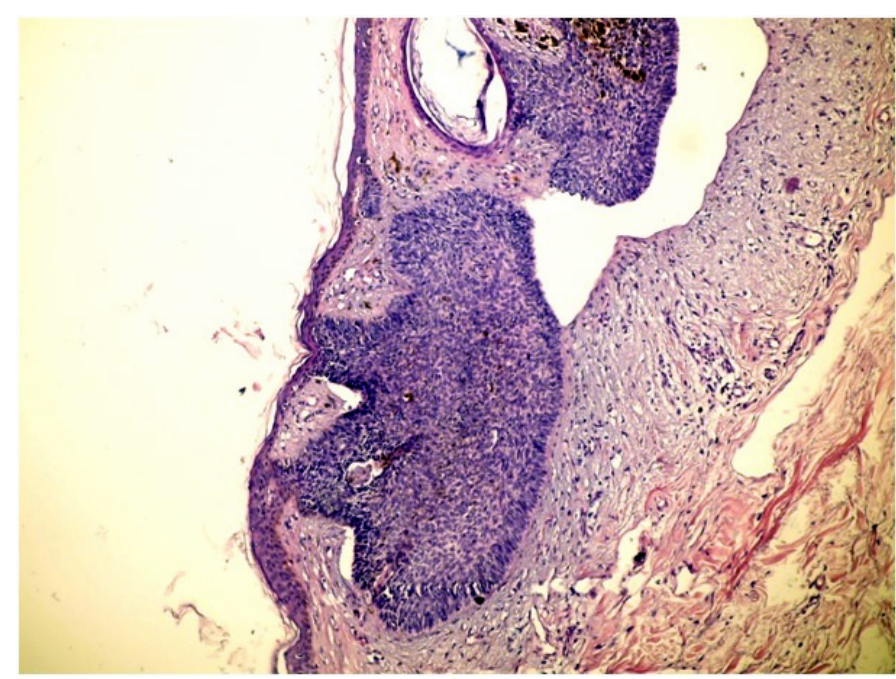

Figure 1c. Nodular type of BCC (H\&E x 100).

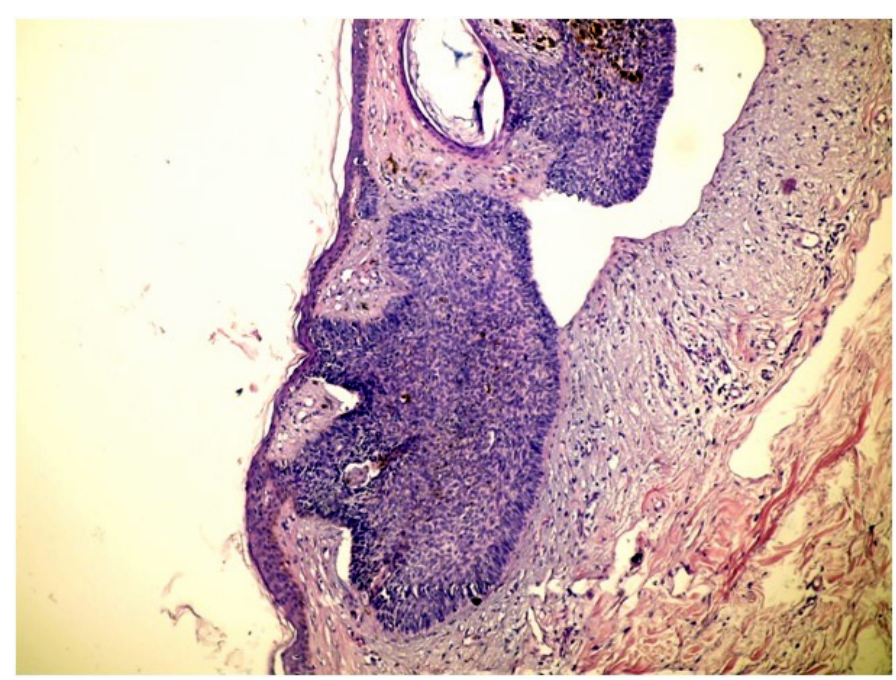

Figure 1d. Solid type of BCC (H\&E x 100).

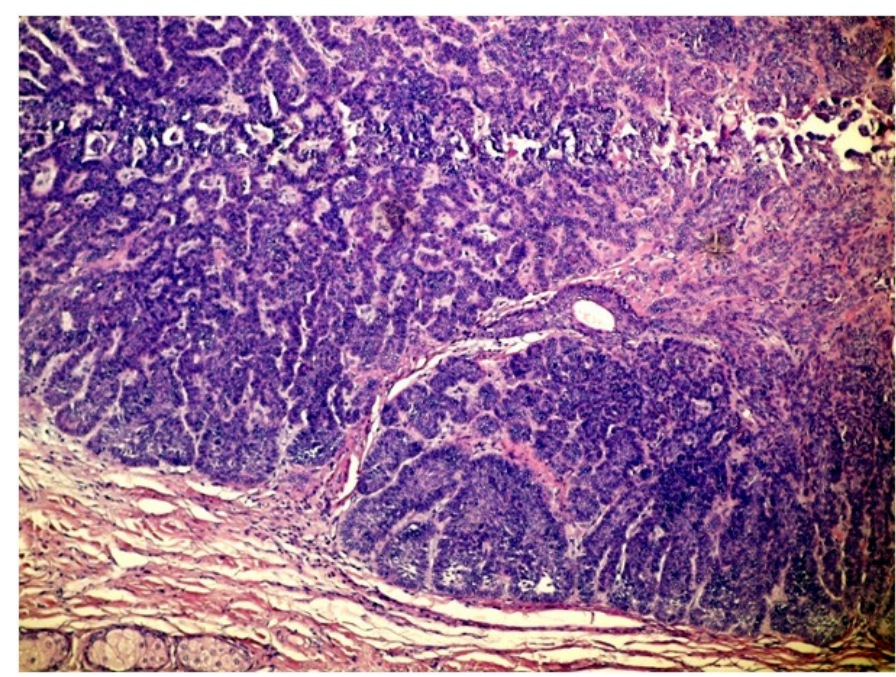

Figure 1e. Adenobasal type of BCC (H\&E x 100). 


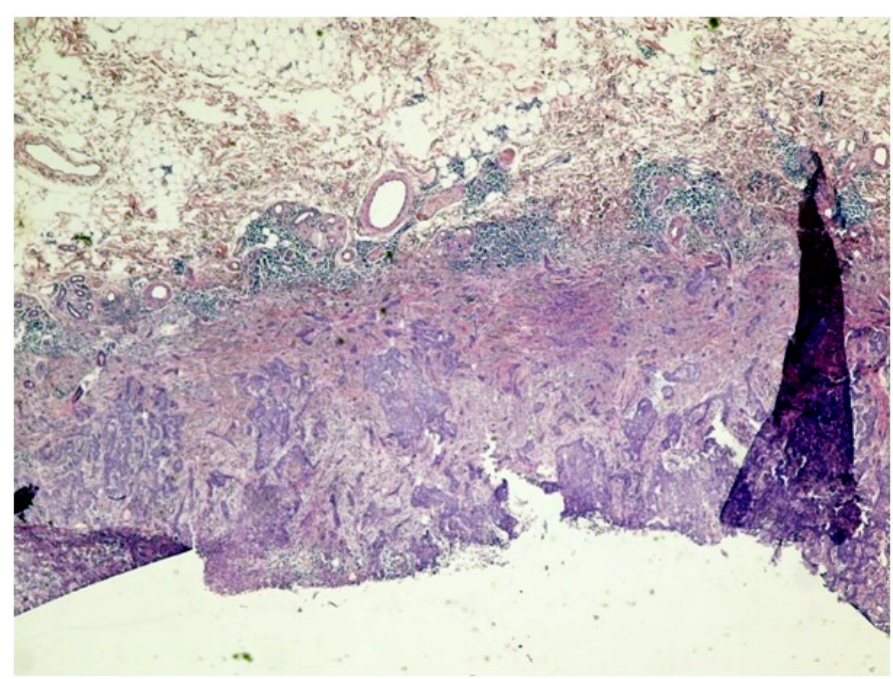

Figure 1f. Infiltrative type of BCC (H\&E x 100).

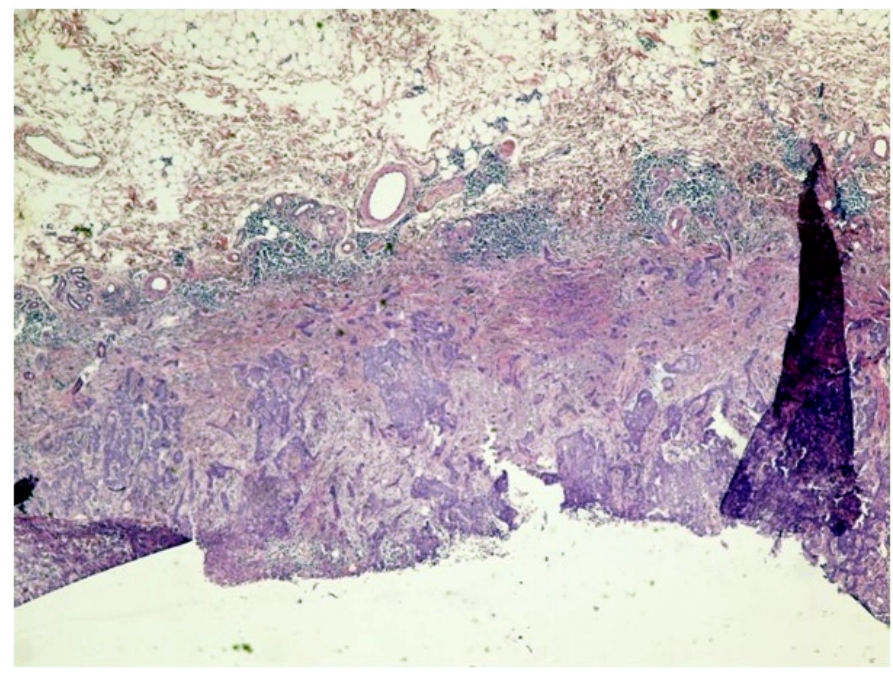

Figure 1g. Infiltrative type of BCC with epidermal ulceration (H\&E x 100).

irregular proliferations of tumor cells usually attached to an atrophic epidermis, with little or no penetration into the dermis. Basaloid cells arranged as elongated strands, only a few layers thick and with little or no palisading peripheral cells referred to as the infiltrative type of BCC.

Patient data included sex, age at diagnosis, and relevant medical history; tumor data included date at diagnosis and anatomic tumor site were derived from patient records. Multiple tumors per patient were included. These were defined as more than one tumor at the same time at whatever anatomic site, or new tumors that were observed and diagnosed at sites other than the primary tumor site. Recurrent tumors were excluded. We chose the tumors just located at head and neck and classified as follows: forehead, nose, cheek, ear-neck and periocular.

\section{Statistical analysis}

Descriptive data are presented as number (percentage) of cases. Comparisons between sex and age groups were performed using the chi-square test or Fisher exact test for categorical variables and the nonparametric Mann-Whitney U test for continuous variables. The association between histopathological subtype and anatomic location was tested using the Kruskal-Wallis test. A multiple comparison test was fitted to assess the independent association between histopathological subtype and anatomic location, adjusting for sex and age. $p=0.05$ was considered to indicate statistical significance (two-sided test).

\section{Results}

During the 2-year study period there was a total of 95 recorded patients with histopathologically confirmed BCC. Sex ratio was almost similar with a slight male predominance (F/M: 46/49) and the mean \pm SD age at excision of a BCC was $69.98 \pm 13.07$ years. The nodular BCC was the most frequently occurring type (23.2\%), followed by the superficial and micronodular types (22.1\%). The micronodular, nodular and superficial BCC occurred more often in males and solid and infiltrative types more often in females. The adenobasal type was seen about equally between the genders (Table 1).

All types of BCC were similar when compared with the localization. Almost all types showed slight predominance for nose localization. The superficial type was the dominant type on the cheek (Table 2) (Figure $2 \mathrm{a}-2 \mathrm{f}$ ). The mean tumor diameter is $8.94 \mathrm{~mm}$ with the range of 0.5 $38 \mathrm{~mm}$. There was a statistically significant difference between the micronodular with the smaller diameter of $5.25 \mathrm{~mm}$ and the other types of BCC diameter $(p=0.01)$. Epidermal ulceration was observed in most of the patients $(77.9 \%)$ and there was not any significant difference in the types of BCC (Table 3).

There was a significant difference between the face-site distribution

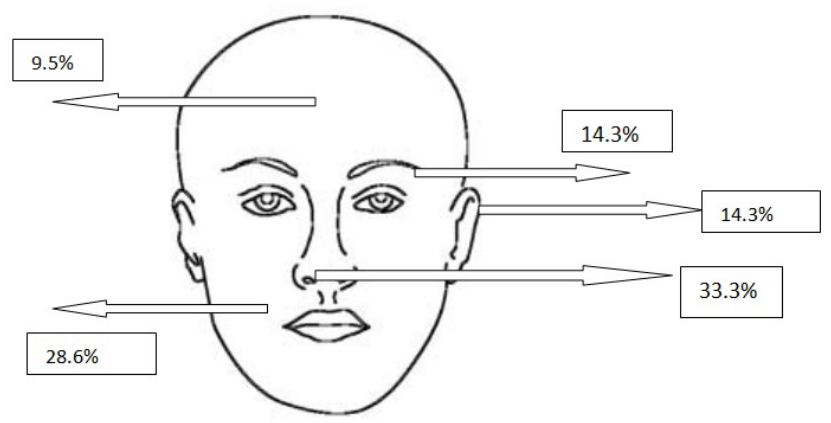

Figure 2a. Localizations of micronodular BCCs

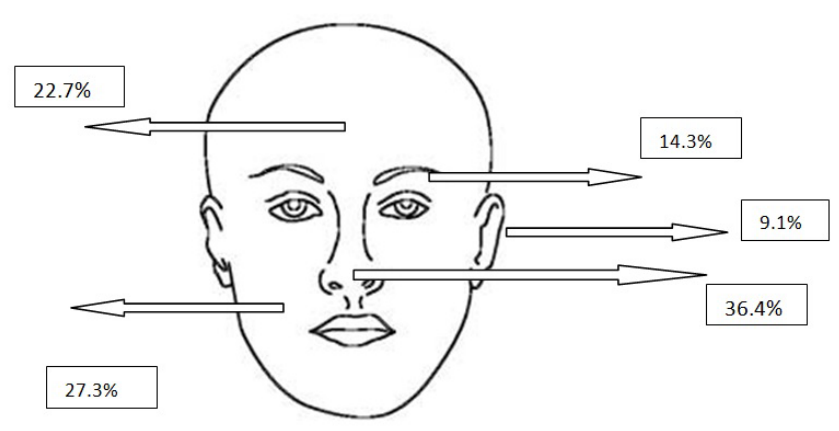

Figure 2b. Localizations of nodular BCCs. 


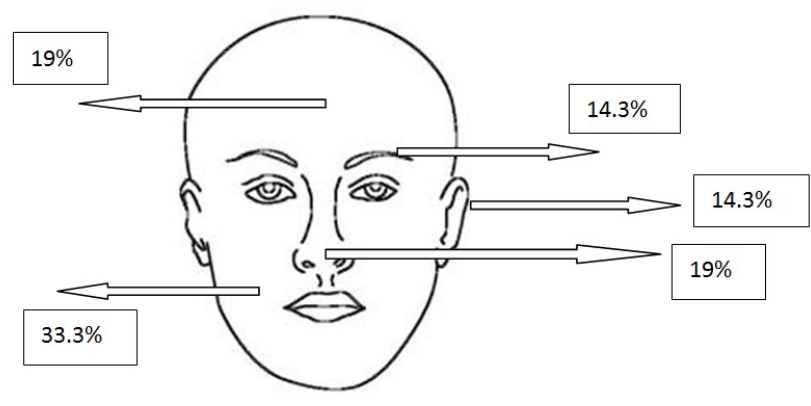

Figure 2c. Localizations of superficial BCCs.

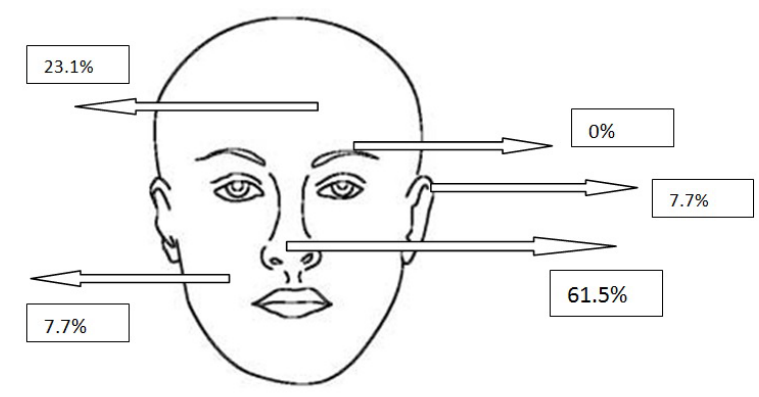

Figure 2d. Localizations of solid BCCs

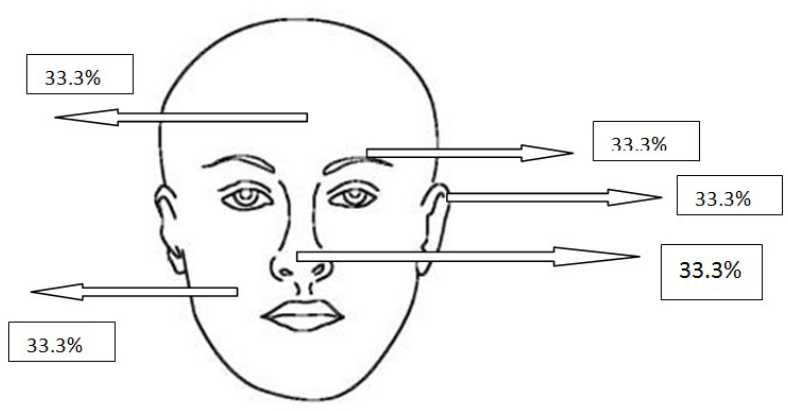

Figure 2e. Localizations of adenobasal BCCs.

and sex. The localization of forehead was dominant in females $(76.5 \%)$ while the cheek and ear- neck localization showed male predominance $(36 \%, 18.2 \%)$ and for the nose localization females were dominant (57.6\%) while ear-neck showed male predominance (81.8\%) (Table 4). There was a significant difference between the face-site distribution and age, the patients with periocular BCC were younger than others $(p<0.05)$. There was not any significant difference between the tumor localization and tumor diameter, and tumor localization and epidermal ulceration.

\section{Discussion}

As in previously published studies, our results are based on a

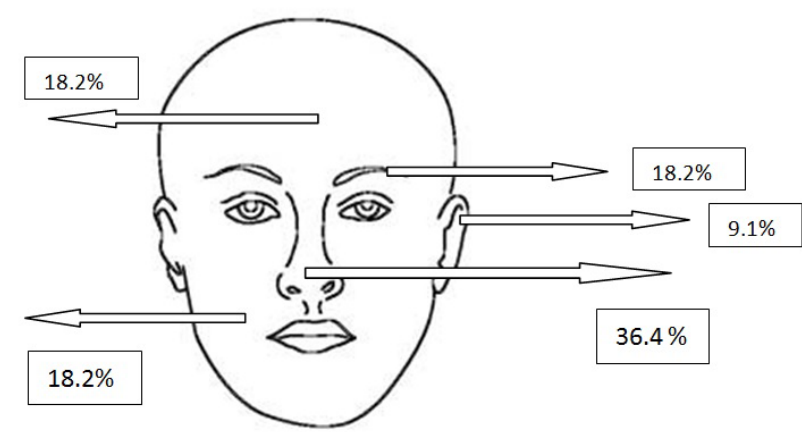

Figure 2f. Localizations of infiltrative BCCs.

retrospective study that included all consecutive cases from a single laboratory: this is the unique centre for dermatopathology in our geographical area. Neither dermatopathology nor clinical textbooks provide extensive information on the differences in age, gender and anatomical distribution of each histological subtype of BCC. Until 1990, most studies focused on the invasiveness and recurrence rates of the various subtypes. Large studies dealing with the demographic characteristics of the histological subtypes were published only after $1995[1,4,14]$. Based on the eight largest studies previously published in the literature [1,4,5,8,14-17], nodular BCCs comprised between $62 \%$ and $70 \%$ of all BCCs, except in the series from New Zealand, [16] in which the nodular type accounted for only $47 \%$ of all BCCs. Superficial BCCs comprised $9-17.5 \%$ and morpheaform BCCs $0.5-16.6 \%$ of carcinomas in those series. It is difficult to make rigorous comparisons between the published studies, mainly because the definition of subtypes varies from one study to another. This is especially true for morpheaform carcinomas. Variations in inclusion criteria could probably account for part of the differences in distribution of BCC subtypes observed in those studies. Latitude and the resulting sun exposure could be another cause of variation in histological subtype. Our results are similar with the published material. As the results of our study nodular BCC was the most frequently occurring type (23.2\%), followed by the superficial and micronodular types $(22.1 \%)$.

This study confirms that there are slight differences between tumor localization on the head and, sex and age distribution. Superficial BCC were more often found in males and preferentially developed on the cheek localization while other types preferring the nose. As in our study it was reported that nose is the most involved area with facial BCC [17]. The micronodular, nodular and superficial BCC occurred more often in males and solid and infiltrative types are more often in females. The adenobasal type was seen nearly equally in genders.

These results suggest that the different histological types are not simple architectural variants, but rather correspond to different subsets of tumors. In the study that was carried on by Scrivener et al. it is mentioned that the superficial BCCs was 3 years lower than that of patients with nodular BCCs [5].

In the published reports on this subject, most authors claim that the etiology between superficial BCC and the other subtypes differs, as was suggested by Maccormack et al. [4] intermittent and probably also intense sun exposure are the best known risk factors for BCC [2-5]. Superficial BCC occur predominantly on the trunk. Because the trunk 
is not continuously exposed to sunlight, intermittent sun exposure may be especially important in the etiology of superficial BCC [5,8,15-17]. On the other hand, nodular BCC most frequently occur in the head/ neck region, and occur more often in men on the ears and scalp, sites that are often not covered by hair. A much higher BCC density on the ears in males as compared with females was also found by others [1]. In the present study we evaluated just the tumors on head and neck localization and could not carried out more investigation on sun exposure effects. All types of BCC were similar when compared with localization. Almost all types showed slight predominance for nose localization as previously published in a study by Janjua and Qureshi [18]. We found that the superficial type most commonly occurred on the cheek although Janjua and Qureshi reported that it was most commonly seen on the lower eyelid [18]. We also determined significant difference between the face- site distribution and sex. The localization of forehead females $(76.5 \%)$ was dominant while the cheek and earneck localization showing male predominance (36\%, 18.2\%). And for the nose localization females were dominant $(57.6 \%)$ while at ear-neck showed male predominance $(81.8 \%)$. We also experienced that there was a significant difference between the face- site distribution and age; the patients with periocular BCC were younger than others. There was not any significant difference between the tumor localization and tumor diameter, and tumor localization and epidermal ulceration.

Our study differs from the others with evaluating the tumor diameter and, epidermal ulceration. The mean tumor diameter is 8.94 $\mathrm{mm}$ with the range of $0.5-38 \mathrm{~mm}$. There was a statistically significant difference between the micronodular with the smaller diameter of 5.25 $\mathrm{mm}$ and the other types of BCC diameter with the $p$ value $p=0.01$. Epidermal ulceration was observed most of the patients (77.9\%) and there was not any significant difference in the types of BCC.

Although our results confirmed those of the previous reports in the literature, large population sized studies should be required to clarify the exact distribution of less common types of BCC of the head and neck region such as superficial variant.

\section{References}

1. Bastiaens MT, Hoefnagel JJ, Bruijn JA, Westendorp RG, Vermeer BJ, et al. (1998) Differences in age, site distribution, and sex between nodular and superficial basal cell carcinoma indicate different types of tumors. J Invest Dermatol 110:880-4. [Crossref]
2. Betti R, Inselvini E, Carducci M, Crosti C (1995) Age and site prevalence of histologic subtypes of basal cell carcinomas. Int J Dermatol 34: 174-176. [Crossref]

3. de Vries E, Louwman M, Bastiaens M, de Gruijl F, Coebergh JW (2004) Rapid and continuous increases in incidence rates of basal cell carcinoma in the southeast Netherlands since 1973. J Invest Dermatol 123: 634-638. [Crossref]

4. McCormack CJ, Kelly JW, Dorevitch AP (1997) Differences in age and body site distribution of the histological subtypes of basal cell carcinoma. A possible indicator of differing causes. Arch Dermatol 133: 593-596. [Crossref]

5. Scrivener Y, Grosshans E, Cribier B (2002) Variations of basal cell carcinomas according to gender, age, location and histopathological subtype. Br J Dermatol 147: 41-47. [Crossref]

6. Kricker A, Armstrong BK, English DR, Heenan PJ (1995) Does intermittent sun exposure cause basal cell carcinoma? a case-control study in Western Australia. Int $J$ Cancer 60: 489-494. [Crossref]

7. Rippey JJ (1998) Why classify basal cell carcinomas? Histopathology 32: 393-398 [Crossref]

8. Sexton M, Jones DB, Maloney ME (1990) Histologic pattern analysis of basal cel carcinoma. Study of a series of 1039 consecutive neoplasms. J Am Acad Dermatol 23: 1118-1126. [Crossref]

9. Czarnecki D, Staples M, Mar A, Giles G, Meehan C (1996) Recurrent nonmelanoma skin cancer in southern Australia. Int J Dermatol 35: 410-412. [Crossref]

10. Milroy CJ, Horlock N, Wilson GD, Sanders R (2000) Aggressive basal cell carcinoma in young patients: fact or fiction? Br J Plast Surg 53: 393-396. [Crossref]

11. Saldanha G, Fletcher A, Slater DN (2003) Basal cell carcinoma: a dermatopathological and molecular biological update. Br J Dermatol 148: 195-202. [Crossref]

12. Rowe DE, Carroll RJ, Day CL Jr (1989) Long-term recurrence rates in previously untreated (primary) basal cell carcinoma: implications for patient follow-up. $J$ Dermatol Surg Oncol 15: 315-328. [Crossref]

13. Lovatt TJ, Lear JT, Bastrilles J, Wong C, Griffiths CE, et al. (2005) Associations between ultraviolet radiation, basal cell carcinoma site and histology, host characteristics, and rate of development of further tumors. J Am Acad Dermatol 52: 468-473. [Crossref]

14. Kopf AW (1979) Computer analysis of 3531 basal-cell carcinomas of the skin. $J$ Dermatol 6: 267-281. [Crossref]

15. Emmett AJ (1990) Surgical analysis and biological behaviour of 2277 basal cel carcinomas. Aust N Z J Surg 60: 855-863. [Crossref]

16. Kikuchi A, Shimizu H, Nishikawa T (1996) Clinical histopathological characteristics of basal cell carcinoma in Japanese patients. Arch Dermatol 132: 320-324. [Crossref]

17. Peres LP, Fiorentin JZ, BaptistaTda S, Fuzina DG, Blanco LF (2012) Clinical and histopathological profile of basal cell carcinoma in a population from Criciúma, Santa Catarina, Brazil. An Bras Dermatol 87: 657-659. [Crossref]

18. Janjua OS, Qureshi SM (2012) Basal cell carcinoma of the head and neck region: an analysis of 171 cases. J Skin Cancer 2012: 943472. [Crossref]

Copyright: $\bigcirc 2015$ Karabulut YY. This is an open-access article distributed under the terms of the Creative Commons Attribution License, which permits unrestricted use, distribution, and reproduction in any medium, provided the original author and source are credited. 